\title{
Teatro de temática científica: uma proposta pedagógica lúdica possível na educação não formal de alunos do ensino fundamental
}

Scientific-themed theater: a playful possible pedagogical proposal on non-formal education of elementary school students

\author{
D. M. S. Assis*; A. L. S. Silva; A. B. Lima; M. F. Serra; W. S. Silva \\ Campus XIX/Licenciatura em Ciências Naturais com habilitação em Biologia, Universidade do Estado do Pará, \\ 68860-000, Salvaterra-Pará, Brasil \\ *davison-assis@hotmail.com
}

(Recebido em 08 de abril de 2016; aceito em 25 de abril de 2016)

\begin{abstract}
O professor de ciências naturais ao trabalhar os conteúdos científicos em sala de aula nem sempre tem sucesso, em grande parte dos casos, devido aos modelos de aulas utilizados. Na tentativa de contornar essa ocorrência, a atuação do docente necessita estar voltada a práticas pedagógicas que viabilizem um melhor ensino e aprendizagem. Dentre os inúmeros recursos didáticos que o professor pode se valer em sala de aula, para tornar suas aulas mais atrativas e dinâmicas, apresentamos neste trabalho o teatro de temática cientifica, que teve como objetivo promover a conscientização acerca do problema de saúde, dengue, através da encenação de uma peça teatral, intitulada: "corram que a dengue vem aí". O trabalho foi desenvolvido com alunos do $5^{\circ}$ ao $7^{\circ}$ ano do ensino fundamental de duas escolas públicas da rede municipal de ensino, no município de Salvaterra, Pará. Ao final da encenação foi aplicado um questionário nas turmas para verificar se ocorreu aprendizagem do tema em questão, e com base em análises das respostas obtidas foi possível concluir que, os alunos tiveram uma melhor compreensão do conteúdo através da encenação teatral, os mesmos despertaram o interesse e ficaram entusiasmados com a forma que foi apresentado o conteúdo. Assim, o teatro configurou-se como um veículo transmissor de conhecimentos científicos, pois o seu uso facilitou a compressão dos alunos acerca do tema abordado.

Palavras-chave: Educação não formal, Teatro Científico, Ludicidade
\end{abstract}

The teacher of natural sciences to work the scientific content in the classroom does not always succeed room largely of cases due to classes models used. In an attempt to overcome this occurrence, the teacher's role needs to be focused on teaching practices that allow a better teaching and learning. Among the many teaching resources that the teacher can make use in the classroom, to make her more attractive and dynamic classes, we present in this work the scientific-themed theater, which aimed to promote awareness of the health problem, dengue through the staging of a play entitled: "run that dengue is coming". The study was conducted with students from 5th to 7th year of elementary school in two public schools in the municipal schools in the municipality of Salvaterra Pará. At the end of staging a questionnaire was applied in the classes to see if there was theme of learning in question, and based on analysis of the responses it was concluded that the students had a better understanding of the content through the theatrical performance, they aroused the interest and raved about the way it was presented content. Thus, the theater was configured as a means of transmitting scientific knowledge, because its use has facilitated the compression of the students about the topic discussed.

Keywords: Informal Education, Scientific Theatre, Playfulness 


\section{INTRODUÇÃO}

É comum observamos nas escolas públicas de ensino fundamental e médio, que o ensino de ciências naturais é visto como algo cansativo e desmotivador, provavelmente os modelos de aulas pouco atrativos utilizados pelo professor reforçam esse pensamento dos educandos. Assim, a aprendizagem dos alunos tende a se realizar de forma mecânica, pois não conseguem relacionar os conteúdos vistos em sala de aula e sua aplicabilidade no cotidiano [1].

A desmotivação dos alunos resulta em um déficit na aprendizagem, e o professor na tentativa de reverter tanto o quadro de desinteresse quanto a falta de participação dos alunos em suas aulas, deve buscar novas metodologias de ensino, como uma possível solução para amenizar ou reverter este quadro. Neste sentido, o teatro utilizado como uma estratégia pedagógica na educação não formal pode constituir-se como um bom aliado, desde que seja utilizada de forma planejada e organizada [2].

A educação não formal destaca-se como uma boa alternativa para promover motivação nos alunos, uma vez que quebra a rotina monótona, muitas vezes, das aulas tradicionais. A esse respeito Gaspar [3] ressalta que a educação não formal inclui o estudo de línguas estrangeiras e de especialidades técnicas, artísticas ou semelhantes, oferecido presencialmente em escolas com horários e períodos definidos, ou em centros culturais: jardins botânicos, parques zoológicos, museus de arte ou de ciências.

Para Montenegro [4] o teatro tem todas as potencialidades para ser utilizado como um veículo transmissor de conceitos científicos, através do qual a aprendizagem é feita de uma forma simples, lúdica e agradável. Além de, se essa atividade for desenvolvida nas escolas, possibilita o desenvolvimento pessoal e amplia o espírito crítico do aluno [2].

Nessa concepção, enquanto alunos de Licenciatura Plena em Ciências Naturais com habilitação em Biologia do Campus XIX da Universidade do Estado do Pará (UEPA) desenvolvemos dentro da disciplina Estágio Supervisionado I - vivências em espaços nãoformais, um projeto-atividade que visou levar aos alunos do ensino fundamental, o teatro como estratégia pedagógica para o ensino de ciências. Para isso, foi criado um texto em uma linguagem teatral, levando em consideração a alta incidência do Aedes aegypti, no município de Salvaterra, ilha de Marajó-PA, com o objetivo de sensibilizar e conscientizar os alunos acerca dessa endemia, pois a dengue está sendo um tema muito repercutido na mídia devido aos altos casos da doença atualmente.

\section{MATERIAL E MÉTODOS}

O Projeto-Atividade foi aplicado em duas escolas (A e B) da rede municipal do município de Salvaterra, com alunos do $5^{\circ}$ ao $7^{\circ}$ ano do ensino fundamental.

A pesquisa desenvolvida neste trabalho foi mista, de caráter qualitativo e quantitativo, onde os dados são coletados e analisados para se estudar um fenômeno em um único trabalho [5].

Inicialmente, foi realizada uma pesquisa exploratória a partir de um levantamento de dados bibliográficos concernentes à dengue, que serviu de base para construção da fala teatral: "Corram que à dengue vem aí", composta de quatro atos coesos e lineares, interpretados pelos cinco autores do projeto.

$\mathrm{Na}$ escola A, a encenação da peça teatral foi apresentada na sala multimídia e na escola B na videoteca da escola. Para apresentação da peça utilizou-se trilha sonora com auxílio de notebook e caixa amplificada das respectivas escolas. Para a encenação da peça teatral foram montados três cenários: a sala de uma residência, um quintal e um posto de Saúde.

Em se tratando de figurino, apenas a caracterização dos personagens "Mosquitão" e "Mosquiteti" foram confeccionadas, os demais são de uso pessoal dos estagiários (Figuras 1 e 2). 


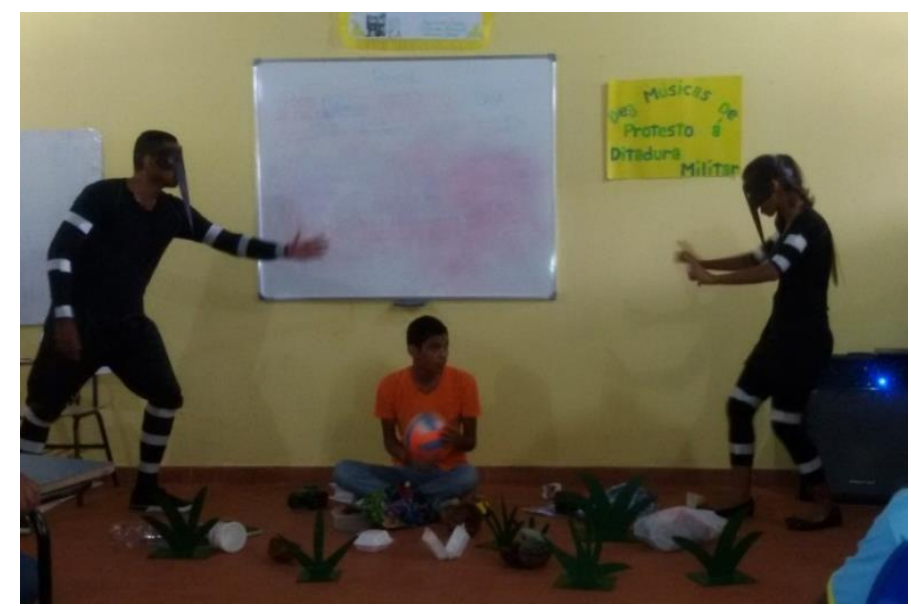

Figura 1 - Encenação da peça "Corram que a dengue vem ai'”

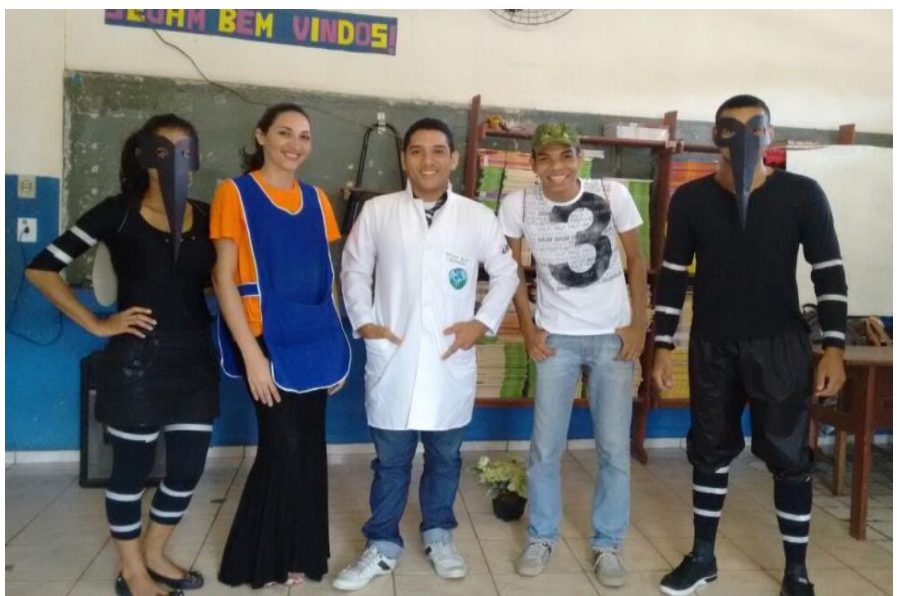

Figura 2 - Elenco da peça teatral

Ao final da encenação da peça, foi utilizado um questionário como instrumento de coleta de dados, que segundo Gil [6] constitui o meio mais rápido e barato para a obtenção de informações, além de não exigir treinamento pessoal e garantir o anonimato.

O questionário foi constituído de oito perguntas, sendo seis abertas e duas fechadas, para identificar se o público alvo compreendeu o tema abordado, e saber a opinião sobre o uso dessa ferramenta como um instrumento pedagógico no ensino de ciências. As perguntas utilizadas no questionário seguem abaixo:

01. Qual o agente causador da dengue?

Um vírus.

Uma bactéria.

Um protozoário.

Um mosquito.

02. Como a dengue é transmitida?

Pela água contaminada por ovos e larvas do mosquito.

Pela picada do mosquito macho infectado.

Pela picada do mosquito fêmea infectada.

Pelo contato com outra pessoa doente.

03. Qual o nome do mosquito transmissor da dengue?

Aedes aegypti

Culex

Anopheles. 


\section{Lutzomyia.}

04. Qual das alternativas abaixo NÃO corresponde aos sintomas da dengue?

Febre alta.

Dor atrás dos olhos.

Diarreia.

Manchas avermelhadas na pele.

05. O que é correto fazer se suspeitar que está com dengue?

Tomaria antitérmico para febre.

Pediria ajuda a um vizinho.

Ficaria de repouso

Procuraria um médico ou pronto-socorro.

06. Qual das ações combatem o mosquito da dengue?

Queimar casca de coco seco.

Uso de raquetes elétricas.

Eliminar vasilhas que podem acumular água parada.

Racionamento de água.

07. O que você achou de ter aprendido sobre a dengue através do teatro?

08. O teatro facilitou sua aprendizagem?

Os métodos de interpretação e análise dos dados utilizados nessa pesquisa são os descritos por [6], em que a análise das perguntas subjetivas, foi feita a partir da decodificação das respostas e as interpretações das objetivas com base na tabulação de dados das respostas corretas, utilizando o programa Excel.

\section{RESULTADOS E DISCUSSÃO}

A peça teatral foi apresentada para alunos em uma linguagem acessível e contextualizada, neste contexto Batalha et al. [1] ressalta que, à medida em que aluno associa o que assisti na peça com o seu cotidiano, a aprendizagem se torna mais significativa, despertando nele a motivação e passa a ver a disciplina de ciências com outro olhar, extinguindo a concepção mecânica que antes possuía a respeito da prática científica, e a partir de então passa a utilizar a ciência como ferramenta de compreensão do mundo que o cerca.

Alguns alunos afirmaram só aula teórica torna o estudo de ciências cansativo, como relata uma aluna, quando indagada se gostou de ter aprendido sobre a dengue através do teatro:

"Sim, porque muita explicação acaba dando sono, então eu acho que essa é a melhor forma" (Aluno A)

De forma semelhante também se posiciona o (Aluno B), quando diz:

"Muitas vezes o professor enche o quadro de texto e isso acaba tornando a aula chata"

Em consonância com esses pensamentos Montenegro [4] fala que, o teatro tem todas as potencialidades para ser encarado como um veículo transmissor de conceitos científicos, através do qual a aprendizagem é feita de uma forma simples, lúdica e agradável.

Durante as apresentações, notamos que o público demonstrou-se disposto e empolgado, acreditamos que pela proposta do uso do teatro, pois na ministração de conteúdos científicos o 
professor necessita se valer de metodologias mais atraentes, conforme Caldas et al. [7] comenta da necessidade de utilização de métodos e estratégias mais atrativos para os alunos.

Ao utilizarmos dessa ferramenta os alunos demostraram-se receptivos, atenciosos e motivados quanto à proposta de ensino, corroborando com a afirmativa de Oliveira e Stoltz [8], quando dizem que "o teatro é extremamente motivador para crianças e adolescentes".

As respostas dos alunos revelaram que os resultados foram satisfatórios, visto que grande parte deles conseguiu responder corretamente as alternativas objetivas, como indica a Tabela 1:

Tabelal- Resultado para o questionário aplicado nas escolas A e B, nas turmas de $5^{\circ}$ ao $7^{\circ}$ ano do Ensino Fundamental.

\begin{tabular}{|c|c|c|c|c|c|c|c|c|}
\hline \multirow[b]{2}{*}{ Escola } & \multicolumn{8}{|c|}{ Resultados dos acertos em porcentagem das questões de 1 a 6} \\
\hline & Ano & $\begin{array}{c}\text { Total } \\
\text { de } \\
\text { alunos }\end{array}$ & $\begin{array}{c}\text { Questão } \\
1\end{array}$ & $\begin{array}{c}\text { Questão } \\
2\end{array}$ & $\begin{array}{c}\text { Questão } \\
\mathbf{3}\end{array}$ & $\begin{array}{c}\text { Questão } \\
4\end{array}$ & $\begin{array}{c}\text { Questão } \\
5\end{array}$ & $\begin{array}{c}\text { Questão } \\
6\end{array}$ \\
\hline $\mathbf{A}$ & $5^{\circ}$ & 23 & $32 \%$ & $29 \%$ & $79 \%$ & $87 \%$ & $92 \%$ & $96 \%$ \\
\hline $\mathbf{A}$ & $6^{\circ}$ & 37 & $48 \%$ & $51 \%$ & $86 \%$ & $89 \%$ & $94 \%$ & $91 \%$ \\
\hline B & $6^{\circ}$ & 25 & $16 \%$ & $52 \%$ & $75 \%$ & $84 \%$ & $66 \%$ & $88 \%$ \\
\hline B & $7^{\circ}$ & 51 & $25 \%$ & $56 \%$ & $94 \%$ & $92 \%$ & $86 \%$ & $94 \%$ \\
\hline
\end{tabular}

Com base na observação da tabela acima, podemos verificar a dificuldade dos alunos nas questões de número 1 quando questionados sobre "qual o agente causador da dengue", e na de número 2 quando questionados sobre "como a dengue é transmitida", provavelmente pelo fato dos alunos associarem a imagem do mosquito, como sendo, também o causador da doença e não somente o transmissor, tanto que um grande percentual dos alunos errou essas duas questões.

Cabe aqui expor que no decorrer da apresentação teatral essa diferença foi abordada, no entanto, os resultados nos mostram que os alunos não conseguiram fazer essa diferenciação, ou indica não ter sido devidamente explorada.

Quanto as questões de números 3, 4, 5 e 6 quando interrogados sobre "qual o nome do mosquito transmissor da doença", "alternativas que não correspondem aos sintomas da doença", "o que fazer se suspeitar que está com dengue", e "qual as ações combatem o mosquito da dengue", respectivamente, os resultados obtidos foram satisfatórios.

Quanto às questões subjetivas de números 7 e 8 , referentes à opinião dos alunos acerca do uso do teatro, como uma proposta didática no ensino de ciências, $100 \%$ se manifestaram a favor do uso dessa estratégia no ensino de ciências, o que indica que os alunos sentiram-se à vontade quanto a proposta de ensino.

A proposta do teatro foi trabalhada na perspectiva da prevenção da dengue, acreditando que os alunos a partir do que foi apresentado na peça possam criar uma postura responsável frente ao combate dessa endemia, em consonância com o pensamento de Moreira e Mirandino [9], que a proposta do teatro científico não é outra senão fazer o público refletir e estimular mudanças no comportamento, trabalhando de maneira didática, no sentido que, o público extraia dela ensinamentos para sua vida.

\section{CONCLUSÃO}

Através do uso do teatro como uma ferramenta didática no ensino de ciências, foi possível constatar que o seu uso nas aulas de ciências é viável, visto que, o público alvo apresentou-se predisposto e empolgado, é uma proposta de ensino que pode ser usada nas escolas para se ter uma aprendizagem mais significativa na disciplina de ciências.

No desenvolvimento do projeto, o teatro configurou-se como um veículo transmissor de conhecimentos científicos, pois o seu uso facilitou a compressão dos alunos acerca do tema abordado; a aprendizagem ocorreu de maneira agradável, devido ao seu perfil lúdico e 
envolvente, e conforme a análise dos questionários a aprendizagem foi produtiva, pois os resultados obtidos atenderam às expectativas dos executores do projeto.

Ao final, os estagiários observaram que a utilização do teatro foi uma excelente escolha, pois a partir do momento em que a peça fora somente anunciada percebemos no comportamento dos alunos empolgação e curiosidade, e consequente pré-disposição, o que contribuiu para a aprendizagem fluir de maneira agradável. Assim, concluímos que o teatro quando bem utilizado pelo professor de ciências configura-se como uma excelente ferramenta de apoio metodológico no processo de ensino e aprendizagem.

\section{REFERÊNCIAS BIBLIOGRÁFICAS}

1. Batalha RRM, Sousa Junior FS, Santos AGD, Souza L, Falconieri AGF. Teatro científico como metodologia motivacional no processo de ensino aprendizagem de ciências. Disponível em: <http://www.annq.org/congresso2011/arquivos/1300240600.pdf〉. Acesso em: 14 jun. 2015.

2. Santos AN, Santos AN. O teatro e suas contribuições para educação infantil na escola pública. XVI ENDIPE - Encontro Nacional de Didática e Práticas de Ensino - UNICAMP. Campinas: Junqueira \& Marin Editores, 2012.

3. Gaspar A. A educação formal e a educação informal em ciências. Disponível em: < http://www.casadaciencia.ufrj.br/Publicacoes/terraincognita/cienciaepublico/artigos/art14_aeducacaof ormal.pdf>. Acesso em: 31 mar. 2016.

4. Montenegro B. O papel do teatro na divulgação científica: A experiência da Seara da Ciência. Disponível em: <http://lapeffs.googlepages.com/F758_p_31a32_Opapeldoteatronadivulga.pdf>. Acesso em: 14 jun. 2015.

5. Creswell JW. Reseach designe: qualitative, quantitative, and mixed methods approaches. 2. ed. Londres: Sage Publications, 2004.

6. Gil AC. Como elaborar projetos de pesquisa. 4. ed. 11. reimpr. São Paulo: Atlas, 2008. 175 p.

7. Caldas AJ, Lima FGC, Leite GMS. O Ensino de Ciências por meio de práticas lúdicas no recreio escolar. Cariri, 2014.

8. Oliveira ME, Stoltz T. Teatro na escola: considerações a partir de Vygotsky. Curitiba: Editora UFPR, 2010.

9. Moreira LM, Marandino M. Teatro de temática científica: conceituação, conflitos, papel pedagógico e contexto brasileiro. Bauru, 2015. 